\title{
Functional and educational outcomes after treatment for intracranial arteriovenous malformations in children
}

\author{
Max J. van Essen ${ }^{1} \cdot$ Kuo Sen Han ${ }^{1} \cdot$ Rob T. H. Lo ${ }^{2}$ Peter Woerdeman ${ }^{1} \cdot$ Albert van der Zwan ${ }^{1,3}$. \\ Tristan P. C. van Doormaal ${ }^{1,3}$
}

Received: 26 April 2018 / Accepted: 31 August 2018 / Published online: 7 September 2018

(C) The Author(s) 2018

\begin{abstract}
Background Arteriovenous malformations (AVMs) in the pediatric population are rare, yet they form the most frequent cause of hemorrhagic stroke in children. Compared to adults, children have been suggested to have beneficial neurological outcomes. However, few studies have focused on other variables than neurological outcomes. This study aims to assess the long-term functional and educational outcomes of children after multimodality approach of treatment for intracranial AVMs.

Methods All children treated in our center between 1998 and 2016 for intracranial AVMs were reviewed. Patient characteristics, as well as AVM specifics, were collected. Functional outcomes were compared using the modified Rankin scale (mRs). Educational levels, using the International Standard Classification of Education (ISCED), were compared to the age-matched general population of the Netherlands.

Results In total, 25 children were included at mean age of 10 years (range 2-16 years). Nineteen patients (76\%) presented with intracranial bleeding. Mean follow-up was $11.5 \pm 5.3$ years (range 4.1-24.4). Four (16\%) of patients were treated with embolization, three (12\%) with microsurgery, and 18 patients $(72 \%)$ received a combination of different treatment modalities. Altogether, 21 (84\%) were embolized, $14(56 \%)$ were treated with microsurgery, and eight (32\%) received stereotactic radiosurgery. One child had a worse mRs at discharge compared to admission; all others improved $(n=11)$ or were stable $(n=13)$. At follow-up, all patients scored a stable or improved mRs compared to discharge, with 23 children (92\%) scoring mRs 0 or 1 . These 23 children followed regular education during follow-up without specialized or adapted schooling. No significant differences in educational level with the age-matched general population were found.

Conclusion This retrospective review shows positive long-term results of both functional and educational outcomes after multidisciplinary treatment of pediatric brain AVMs.
\end{abstract}

Keywords Arteriovenous malformation $\cdot$ Pediatrics $\cdot$ Multimodality treatment $\cdot$ Functional outcomes $\cdot$ Development $\cdot$ Education

\section{Introduction}

Arteriovenous malformations (AVMs) in the pediatric population are rare, yet they form the most frequent cause of hemorrhagic stroke in children [15]. Besides rupture and

This article is part of the Topical Collection on Pediatric Neurosurgery

Tristan P. C. van Doormaal

T.P.C.vanDoormaal@umcutrecht.nl

1 Department of Neurosurgery, University Medical Center Utrecht, Heidelberglaan 100, 3584 CX Utrecht, The Netherlands

2 Department of Radiology, University Medical Center Utrecht, Heidelberglaan, 100 Utrecht, The Netherlands

3 Brain Technology Institute, Yalelaan, 44 Utrecht, The Netherlands subsequent bleeding out of the AVM, children can also present with seizures and headaches [11].

Because not all AVMs are symptomatic, real incidence rates remain unclear. Prevalence of symptomatic AVMs is estimated to be between 0.06 and $0.11 \%$ in the total population [11], with mean age of diagnosis of 31.2 years [13]. Due to the longer lifespan, it is believed that children with AVMs would have a higher lifetime risk of bleeding than adults [10]. Furthermore, after treatment, re-bleeding occurs in $2.71 \%$ $(\mathrm{SD} \pm 1.32 \%)$ of cases, which adds to the risk of this specific population [5]. Pathophysiology of genesis and rupture of AVMs is considered to be multifactorial [21]. Although congenital origin is considered an important factor, growing understanding on angiogenesis with theories on hormonal influences is also starting to become more accepted [21]. 
Upon bleeding, up to one third of children are comatose, and approximately half of patients have a neurological deficit [5]. The possible life threatening conditions, as a result, sometimes call for intensive care and emergency intervention. In general, a multidisciplinary approach of treatment is used to get the best possible results. Complete obliteration is considered an important purpose of treatment, as partial occlusion of AVMs is associated with re-bleeding. Possible modalities to reach this objective are embolization, microsurgery, and radiosurgery. These all have different advantages and disadvantages, and combinations could result in non-inferior outcomes [9, 17, 21]. However, due to the low incidence rates and lack of comparative trials, decision making on which combination is most appropriate remains largely experience- and expert-based.

Children have been suggested to have beneficial neurological outcomes [17], especially compared to adults [20]. Previous studies investigating cognitive outcomes after pediatric intracranial hemorrhage (ICH) used various questionnaires, as well as educational placement as outcome for cognitive function [1, $6,12,16]$. Educational level and followed schooling might contain a natural and comprehensive overview of cognitive functioning as there is a strong relationship between these two $[2,8]$. To our knowledge, no single study has investigated cognitive outcome specifically in children treated for intracranial AVMs. Therefore, the effects of AVMs, eventual bleeding, and treatment on intellectual capacity remain somewhat unclear. The present study aims to assess the cognitive function by educational outcomes of children after multimodality approach of treatment for intracranial AVMs.

\section{Methods}

All children who underwent any form of treatment at our center for an intracranial AVM between 1998 and 2016 were reviewed. This specific timeframe was chosen so that a meaningful assessment of long-term follow-up could be done. Data were collected by using the digital medical records and by telephone call contact with patients or their parents. All patients who met the following criteria were included: 1) any form of treatment for intracranial AVM; 2) age below 18 at time of first treatment. No exclusion criteria were used.

\section{Variables}

We collected patient age (years), gender, and presenting symptoms. Additionally, AVM size, localization, and the presence of deep venous drainage were obtained, and each AVM was graded following the Spetzler-Martin grading system (SMG) [22]. All treatment modalities used for each patient were reviewed, and we distinguished primary treatment and following treatments. Occlusion rates were obtained by trained radiologists as part of normal follow-up. The modified Rankin scale (mRs), adjusted for children, was used to score neurological disability [4]. At admission, discharge and in followup, mRs scores were collected in order to assess the efficacy of treatment. MRs higher than 2 was considered an unfavorable outcome. Additionally, the educational career of each patient was mapped out to assess cognitive functional outcome. We recognized severe neurological impairment and death as result of treatment as major complications.

\section{Educational grading}

As a control group for highest achieved educational levels, we used the general population of the Netherlands, matched by age. This data was collected from a public database (Dutch Central Bureau for Statistics, accessed November 1, 2017) [7]. The educational system in the Netherlands can be divided roughly into primary, different levels of secondary, and tertiary education, following the International Standard Classification of Education (ISCED) 2011 [18]. However, ISCED level 4 is not present in the Dutch schooling system. Therefore, we chose to classify educational levels in lower, intermediate, and high education, in order to come to a meaningful comparison. Lower education hereby corresponds to primary and lower secondary education (ISCED level 1 and 2), intermediate education corresponding to upper secondary education (ISCED level 3), and high education to tertiary education (ISCED level 5 and 6).

\section{Statistical analysis}

Statistical analysis was conducted using IBM SPSS statistics 24. To determine significant differences in the distribution of baseline characteristics we used the following tests: 1) Fisher tests for binary variables if the expected value was below five; 2) chi-squared tests if the expected value was five or higher; 3 ) and Student's $t$ test was used for all continuous variables. To reveal potential predictors, univariate analysis was done by using logistic regression. For all tests, $p$ values below 0.05 were considered as statistical significant.

\section{Results}

\section{Demographics of study population}

In total, 25 children were included at mean age of 10 years (range 2-16 years). Demographics, Spetzler-Martin grades, and $\mathrm{mRs}$ at admission are summarized in Table 1. Nineteen patients $(76 \%)$ presented with intracranial hemorrhage. The six patients with unruptured AVMs presented with headaches $(n=3)$, seizures $(n=1)$, and a defect in the skull $(n=1)$, and one patient was a coincidental finding. Four (16\%) patients were treated in the acute setting on the same day as the 
Table 1 Patient demographics, mRs at admission, and radiological characteristics

\begin{tabular}{|c|c|c|c|}
\hline & $N$ & $\%$ & Test \\
\hline Patients & 25 & & \\
\hline Age & 10.5 years & SD 3.7 & \\
\hline Male & 13 & $52 \%$ & $p=1.0$ \\
\hline \multicolumn{4}{|l|}{ Presentation } \\
\hline Bleeding & 18 & $72 \%$ & \\
\hline Headache & 3 & $12 \%$ & \\
\hline Seizure & 2 & $8 \%$ & \\
\hline Other & 2 & $8 \%$ & \\
\hline \multicolumn{4}{|l|}{$\mathrm{mRs}$ presentation } \\
\hline 0 & 4 & $16 \%$ & \\
\hline 1 & 7 & $28 \%$ & \\
\hline 2 & 1 & $4 \%$ & \\
\hline 3 & 2 & $8 \%$ & \\
\hline 4 & 3 & $12 \%$ & \\
\hline 5 & 8 & $32 \%$ & \\
\hline 6 & 0 & $0 \%$ & \\
\hline \multicolumn{4}{|l|}{ AVM characteristics } \\
\hline Ruptured & 19 & $76 \%$ & $p=0.016^{*}$ \\
\hline Size $<3 \mathrm{~cm}$ & 11 & $44 \%$ & \\
\hline Size $3-6 \mathrm{~cm}$ & 12 & $48 \%$ & \\
\hline Size $>6 \mathrm{~cm}$ & 2 & $8 \%$ & \\
\hline Infratentorial & 5 & $20 \%$ & \\
\hline Deep venous drainage & 10 & $40 \%$ & \\
\hline Associated aneurysm & 3 & $13 \%$ & \\
\hline \multicolumn{4}{|l|}{ Spetzler-Martin grade } \\
\hline 1 & 3 & $12 \%$ & \\
\hline 2 & 9 & $36 \%$ & \\
\hline 3 & 10 & $40 \%$ & \\
\hline 4 & 1 & $4 \%$ & \\
\hline 5 & 2 & $8 \%$ & \\
\hline
\end{tabular}

$m R s$ modified Rankin scale, $A V M$ arteriovenous malformation

*A $p$ value $<0.05$ was considered statistically significant

hemorrhage. Mean follow-up was 11.5 years (range 4.124.4 years) (SD 5.3). Mean age at follow-up was 22.0 years (range 12.4-33.7 years) (SD 5.8).

\section{Genetics}

One patient was diagnosed with Wyburg-Mason syndrome. Another patient had unspecified congenital psychomotor impairment and diagnosed early in life with an accompanying AVM. Furthermore, two patients had family history of multiple family members with subarachnoidal hemorrhage or AVMs, yet without a syndromal diagnosis. Finally, one patient had accompanying Marfan syndrome.

\section{Treatment}

Embolization, surgical resection, and stereotactic radiosurgery (SRS) using a linear accelerator or gamma-knife were used to treat the AVMs (Table 2). Embolization was the initial treatment in $20(80 \%)$ patients, with the remaining five $(20 \%)$ initially treated by microsurgical resection. SRS in this series was not used as initial treatment mode. In total, $21(84 \%)$ patients underwent embolization, 14 $(56 \%)$ were operated, and eight $(32 \%)$ had subsequent SRS. The majority of the children $(76 \%)$ were treated with multiple modalities. In three out of four cases of acute intervention, microsurgery was the primary treatment, and embolization was performed in the fourth. The two cases presenting with epilepsy were initially managed with antiepileptic drugs. In both cases, the AVM as epileptic focus was thereafter treated by a combination of embolization and microsurgery. Afterwards, the seizures resolved in both patients, and anti-epileptic drugs were discontinued. Upon discharge, all patients would have access to rehabilitation support, which is part of the standard of care. The extent of this support differed between patients, according to the specific needs. The follow-up regimen consisted of angiographies to assess the extent of the occlusion, as well as outpatient control visits. In the first year post-treatment, cerebral angiography would take place yearly. Later on, the interval was extended, with a final angiography at the age of 21 . Additional cerebrovascular imaging was performed if indicated.

\section{Outcome}

Post-treatment angiography showed complete occlusion of the AVM in 19 of 25 patients (76\%). The mean obliteration percentage of the total cohort was $93.4 \%$ (SD 15.5\%). Acute treatment as well as the form of primary treatment was not associated with lower occlusion rates (both $p=1.00$ ). However, AVMs with a SMG lower than 3 had higher occlusion rates $(p<0.001)$ and more often complete obliteration $(p=0.04)$. Upon treatment, two $(8 \%)$ children experienced temporary increase of neurological deficits, and one (4\%) had a new mild coordinative difficulty in one leg. Furthermore, three (12\%) patients experienced posttreatment hydrocephalus. In two of these, this was due to the intracranial hemorrhage. In the third case, besides the patients preexisting psychomotor retardation, no other explanation was found. All patients with hydrocephalus needed an additional ventriculoperitoneal shunt. Re-bleeding occurred in three $(12 \%)$ patients, of which two could be seen as AVM recurrence after initial complete AVM obliteration. All needed additional treatment. In the total cohort, no major complications or deaths occurred. 
Table 2 All used treatment combinations, grouped in unruptured and ruptured AVM status, with accompanying overall occlusion rate

\begin{tabular}{llllc}
\hline Modalities & $\begin{array}{l}\text { Total, } \\
n(\%)\end{array}$ & $\begin{array}{l}\text { Unruptured, } n(\% \\
\text { total })\end{array}$ & $\begin{array}{l}\text { Ruptured, } n(\% \text { of } \\
\text { total })\end{array}$ & $\begin{array}{l}\text { Occlusion rate } \\
\%\end{array}$ \\
\hline Embolization & $4(16)$ & $2(33)$ & $2(11)$ & 83 \\
Embolization-Microsurgery & $9(36)$ & $2(33)$ & $7(37)$ & 100 \\
Embolization-SRS & $7(28)$ & $1(17)$ & $6(32)$ & 90 \\
Microsurgery & $3(12)$ & $1(17)$ & $2(11)$ & 98 \\
Microsurgery-Embolization & $1(4)$ & 0 & $1(5)$ & 100 \\
Microsurgery-SRS & $1(4)$ & 0 & $1(5)$ & 100 \\
Total & 25 & 6 & 19 & 94 \\
\hline
\end{tabular}

$S R S$ stereotactic radio surgery
Comparing mRs at admission and at discharge, $52.6 \%$ of the children with a ruptured AVM improved $(n=10)$ and $5.3 \%(n=1)$ scored worse. Of the patients with unruptured AVMs, $16 \%$ improved $(n=1)$ and none scored worse. At follow-up, five patients had persisting and stable neurological deficits, and three children had persisting but improved deficits. Six of these patients had mild deficits like visual field deficits $(n=5)$, diplopia $(n=1)$, and the previously mentioned coordinative difficulties $(n=1)$ with no interference in their daily life. In the other two patients, remaining deficits were hemiparesis $(n=1)$ and mental retardation $(n=1)$. The patient with mental retardation was known with these disabilities prior to treatment. Finally, in follow-up, all patients scored a stable or improved mRs compared to discharge. Of the children, $91.3 \%$ had either mRs 0 or 1 , whereas the other two scored $\mathrm{mRs} 2$ and mRs 3 respectively. The $\mathrm{mRs}$ scores at admission, discharge, and follow-up are arranged in Fig. 1.

\section{Education}

During follow-up, 23 of the 25 children (92\%) followed regular education without specialized or adapted schooling. One patient needed adjustments for physical disabilities with normal educational levels. Only one patient, who was known to have mental retardation previous to treatment, was in need of adaptive education. Furthermore, eight $(34.8 \%)$ patients attained tertiary education, which we scored as high education. Of two children, specific educational levels were not obtainable, and only a simple assessment could be made. Therefore, we did not implicate these children in the comparison with the general population. The distribution of different educational levels of this case series in comparison to agematched peers is shown in Fig 2. No differences were found.

\section{Statistical analysis}

In this cohort, there was no significant relationship between unfavorable neurological or functional outcome $(\mathrm{mRs}>2$, found in two patients) and bleeding of the AVM, size (grouped following the SMG), or location (eloquent versus noneloquent of the AVM, modified Rankin scale at admission, recurrence or re-beeding, and used treatment modalities (all $p>0.05$ ). Although patients with SMG below 3 more often had complete obliteration, this association was not significant in logistic regression $(p>0.05)$. Reckoning the fact that rebleeding only occurred in three cases, incomplete occlusion of the AVM was not associated with re-bleeding $(p=1)$.
Fig. 1 Modified Rankin scores at admission, at discharge, and in long-term follow-up. Numbers in the different boxes represent the corresponding amount of children with that specific mRs.

Proportions of $\mathrm{mRs}$ scores at different moments in course of treatment and follow-up. mRs modified Rankin score. Admission represents $\mathrm{mRs}$ at admission. Discharge represents $\mathrm{mRs}$ at discharge. Follow-up represents $\mathrm{mRs}$ at the last moment of follow-up, average after 11.5 years

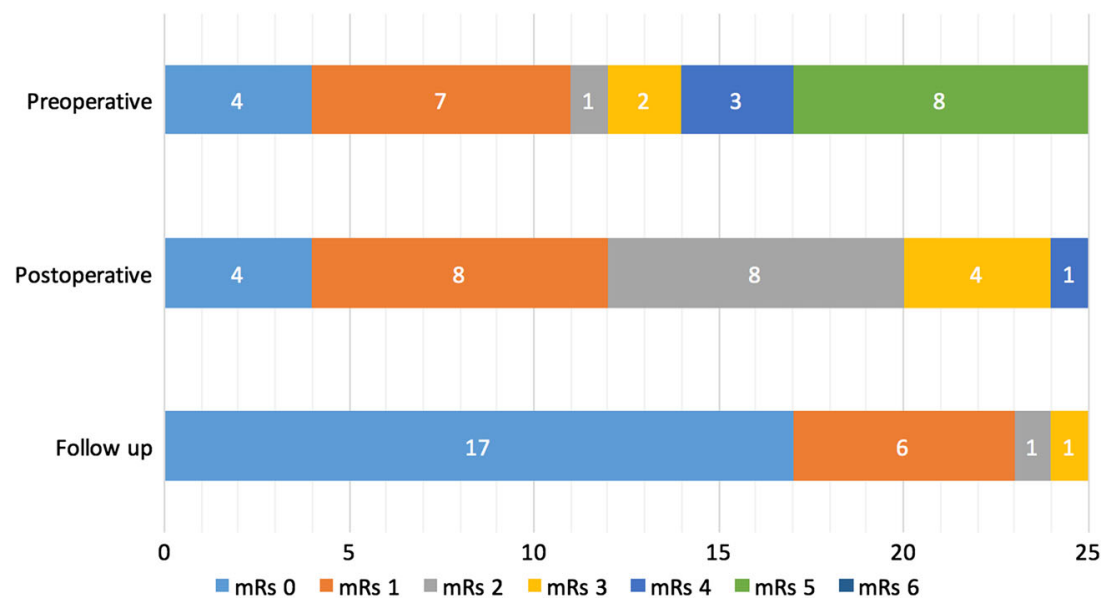




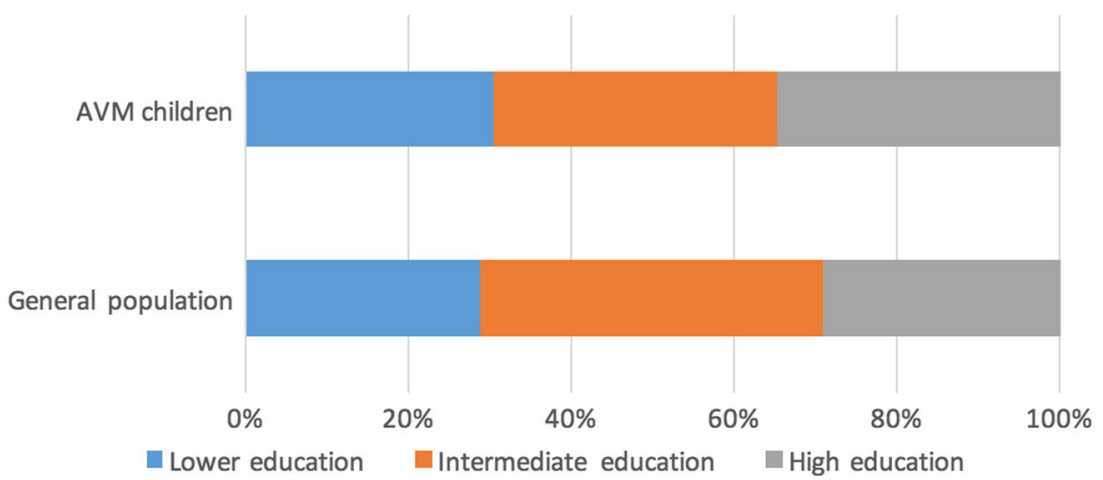

Fig. 2 Distribution of educational levels of children treated for AVMs compared with the general population of the Netherlands. Proportions of educational levels. Lower education corresponding with ISCED levels 1 and 2 , intermediate education corresponding with ISCED level 3, high education corresponding with ISCED levels 5 and 6. Educational levels of two children were not obtainable, resulting in educational levels of 23 children. The total general population of the Netherlands in the age-group $15-35$ years is $4,178,000$ persons.

\section{Discussion}

This retrospective review shows positive long-term results of both functional and educational outcomes after a multidisciplinary approach of treatment in pediatric brain AVMs. This study investigated educational achievement, as this both reflects cognitive function and is particularly important for the quality of life of these patients. Almost all patients were able to continue their normal lives with minimal to no remaining neurological disabilities or cognitive restrictions. In comparison to age-matched peers, the educational levels of these children showed no difference.

Since the long-term functional outcome of the cohort was very good, it was impossible to find a predictor for unfavorable outcome. Because of the same reason and because less than a third of the patients were treated with a single strategy, no single treatment strategy was found superior in this case series. These results may confirm the importance of a multidisciplinary approach of this rather serious condition in the pediatric population. To our knowledge, there currently are no studies available comparing results of different treatment modalities and combinations. However, combining modalities is suggested only to improve clinical outcomes $[9,17]$. A recent study (2016) on multimodality treatment of pediatric brain AVMs showed results very similar to this study, with the majority of pediatric patients scoring mRs between 0 and 2 at follow-up [17]. Innovation in different treatment options has been held accountable for a significant part of the improvement of results over the years [21]. A striking example is the decline in mortality rates. Early studies reported death following treatment in up to $25 \%$ [14]. However, most studies these days report mortality of $5 \%$ or even less $[11,14]$. Adopting this trend, no children died in this study during admission or follow-up. Additional information about the amount of children who die at home or before intervention can take place would be useful to further determine outcome of children with AVM. Based on the administration of our hospital (region of 3.5 million people) combined with data of the Dutch Central Bureau of Statistics (CBS), a case of spontaneous death in a child because of an AVM rupture is highly unlikely to have occurred in our hospital in the past 19 years.

At presentation, prognosis may seem unclear to parents and clinicians. AVM bleeding can be life threatening and sometimes even requires emergency treatment. This study shows that in our cohort, neurological as well as educational outcomes are promising after multidisciplinary approach of treatment. Analysis of patient- and AVM-related factors did not result in significant associations with differences in outcomes. This is in contrast with some of the existing literature, in which associated aneurysms, deep venous drainage, and partial occlusion are suggested to be associated with higher chance of re-bleeding and worse outcomes [5]. Furthermore, comatose condition at presentation has been associated with less favorable outcomes [5]. However, these correlations were not found in this study; although eight patients $(34.8 \%)$ had a mRs of 5 at admission, seven of these (87.5\%) had mRs 0 in follow-up, and all followed normal education. Moreover, the distribution of educational levels among all treated children gives the impression that the learning abilities have also not been affected. In total, eight patients (34.8\%) achieved high education with bachelor's and even master's degrees. This is more or less equal to $29.1 \%$ in the general population. These results are noteworthy, as some studies on pediatric ICH note significantly lower cognitive as well as educational function in follow-up [11, 15]. It has also been suggested that over half of these children need additional educational services beyond 12 months after ICH [12]. However, these findings cannot be supported by our case series, where only $8 \%$ needed additional educational services, and education seemed not to be affected. It has also been described that the need of specialized education and corrective devices decreases health-related 
quality of life (HRQL) in these children [1]. As education and schooling make up a considerable part of children's life, the ability to follow regular schooling is very important. This underlines the significance of these favorable results.

Due to the low incidence rates, true evaluation of the effects of any form of treatment and neurological and cognitive outcomes remains difficult. With 25 patients in as many years and multiple options for treatment, we still depend largely on retrospective analyses, which is also the main limitation of this study. The fact that some of the previously described factors related to changes in outcomes were not found significantly associated, might very well be based on the small size of this cohort. Presumably, a larger population may have demonstrated a wider range of outcomes. In addition, the use of a subjective scoring system should also be noted as a possible bias. The modified Rankin scale is a validated adult scoring system and commonly used in clinical trials [3, 23]. Although several previous studies have used an adjusted modified Rankin scale for children, this scoring system has yet to be validated in the pediatric population [4]. Additionally, the subjective nature of the scale holds possible reporting bias [3, 19]. Furthermore, by evaluating educational levels, we did not differentiate between different aspects of cognitive functioning. For this kind of evaluation, a validated measurement of cognitive function should have been used. Therefore, we would like to emphasize that these educational outcomes should not directly be translated to cognitive outcomes. Although, as described earlier, there is a strong relation between the two, they are not equivalent. Therefore, results should be interpreted with consideration of these limitations and remarks. These outcomes should also be translated only to countries with comparable standard of care and rehabilitative services, with similar accessibility. The fact that two out of three patients with a rebleeding had initial complete obliteration demonstrates the importance of post-treatment follow-up and angiographies.

\section{Conclusion}

This retrospective review shows satisfactory long-term results of both functional and educational outcomes after multidisciplinary treatment of pediatric brain AVMs. Unfortunately, it was impossible to find predictors for either better or worse outcomes. However, these findings might contribute to the existing belief that clinical outcomes seem to be favorable among children as compared to adults.

\section{Compliance with ethical standards}

Conflict of interest All authors certify that they have no affiliations with or involvement in any organization or entity with any financial interest (such as honoraria; educational grants; participation in speakers' bureaus; membership, employment, consultancies, stock ownership, or other equity interest; and expert testimony or patent-licensing arrangements) or non-financial interest (such as personal or professional relationships, affiliations, knowledge, or beliefs) in the subject matter or materials discussed in this manuscript.

Ethical approval This article does not contain any studies with human participants performed by any of the authors. Our institutional ethical board exempted this study, due to the retrospective nature, from the requirement of formal consent.

Open Access This article is distributed under the terms of the Creative Commons Attribution 4.0 International License (http:// creativecommons.org/licenses/by/4.0/), which permits unrestricted use, distribution, and reproduction in any medium, provided you give appropriate credit to the original author(s) and the source, provide a link to the Creative Commons license, and indicate if changes were made.

\section{References}

1. Abecassis IJ, Nerva JD, Barber J, Rockhill J, Ellenbogen RG, Kim LJ, Sekhar LN (2016) Toward a comprehensive assessment of functional outcomes in pediatric patients with brain arteriovenous malformations: the Pediatric Quality of Life Inventory. J Neurosurg Pediatr 18(5):611-622

2. Ardila A, Ostrosky-Solis F, Rosselli M, Gómez C (2000) Agerelated cognitive decline during normal aging: the complex effect of education. Arch Clin Neuropsychol 15(6):495-513

3. Banks JL, Marotta CA (2007) Outcomes validity and reliability of the modified Rankin scale: implications for stroke clinical trials: a literature review and synthesis. Stroke 38(3):1091-1096

4. Bigi S, Fischer U, Wehrli E et al (2011) Acute ischemic stroke in children versus young adults. Ann Neurol 70(2):245-254

5. Blauwblomme T, Bourgeois M, Meyer P, Puget S, Di Rocco F, Boddaert N, Zerah M, Brunelle F, Sainte RC, Naggara O (2014) Long-term outcome of 106 consecutive pediatric ruptured brain arteriovenous malformations after combined treatment. Stroke 45(6): 1664-1671

6. Blom I, De Schryver ELLM, Kappelle LJ, Rinkel GJE, JennekensSchinkel A, Peters ACB (2003) Prognosis of haemorrhagic stroke in childhood: a long-term follow-up study. Dev Med Child Neurol 45(4):233-239

7. CBS Statline (2017) CBS StatLine - Bevolking; hoogst behaald onderwijsniveau; geslacht, leeftijd en herkomst. statline.cbs.nl Bevolking; hoogst behaald onderwijsniveau; geslach

8. Clark CR, Paul RH, Williams LM, Arns M, Fallahpour K, Handmer C, Gordon E (2006) Standardized assessment of cognitive functioning during development and aging using an automated touchscreen battery. Arch Clin Neuropsychol 21(5):449-467

9. Darsaut TE, Guzman R, Marcellus ML et al (2011) Management of pediatric intracranial arteriovenous malformations: experience with multimodality therapy. Neurosurgery 69(3):540-556

10. Ding D, Starke RM, Kano H et al (2017) International multicenter cohort study of pediatric brain arteriovenous malformations. Part 1: predictors of hemorrhagic presentation. J Neurosurg Pediatr 19(2):127-135

11. El-Ghanem M, Kass-Hout T, Kass-Hout O, Alderazi YJ, Amuluru K, Al-Mufti F, Prestigiacomo CJ, Gandhi CD (2016) Arteriovenous malformations in the pediatric population: review of the existing literature. Interv Neurol 5(3-4):218-225

12. Hawks C, Jordan LC, Gindville M, Ichord RN, Licht DJ, Beslow LA (2016) Educational placement after pediatric intracerebral hemorrhage. Pediatr Neurol 61:46-50 
13. Hofmeister C, Stapf C, Hartmann A, Sciacca RR, Mansmann U, TerBrugge KG, Lasjaunias PL, Mohr JP, Mast H, Meisel J (2000) Demographic, morphological, and clinical characteristics of 1289 patients with brain arteriovenous malformation. Stroke 31(6):1307-1310

14. Kondziolka D, Humphreys RP, Hoffman HJ, Hendrick EB, Drake JM (1992) Arteriovenous malformations of the brain in children: a forty year experience. Can J Neurol Sci 19(1):40-45

15. Lo WD (2011) Childhood hemorrhagic stroke: an important but understudied problem. J Child Neurol 26(9):1174-1185

16. Murphy LK, Compas BE, Gindville MC, Reeslund KL, Jordan LC (2017) Cognitive functioning over 2 years after intracerebral hemorrhage in school-aged children. Dev Med Child Neurol 59(11): 1146-1151

17. Nerva JD, Kim LJ, Barber J, Rockhill JK, Hallam DK, Ghodke BV, Sekhar LN (2016) Outcomes of multimodality therapy in pediatric patients with ruptured and unruptured brain arteriovenous malformations. Neurosurgery 78(5):695-707

18. OECD, European Union, UNESCO Institute for Statistics (2015) SCED 2011 Operational manual: guidelines for classifying national education programmes and related qualifications. doi: https://doi. org/10.1787/9789264228368-en

19. Quinn TJ, Dawson J, Walters MR, Lees KR (2009) Reliability of the modified Rankin scale: a systematic review. Stroke 40(10):3393-3395

20. Sanchez-Mejia RO, Chennupati SK, Gupta N, Fullerton H, Young WL, Lawton MT (2006) Superior outcomes in children compared with adults after microsurgical resection of brain arteriovenous malformations. J Neurosurg 105(2 Suppl):82-87

21. Shtaya A, Millar J, Sparrow O (2017) Multimodality management and outcomes of brain arterio-venous malformations
(AVMs) in children: personal experience and review of the literature, with specific emphasis on age at first AVM bleed. Childs Nerv Syst 33(4):573-581

22. Spetzler RF, Martin NA (1986) A proposed grading system for arteriovenous malformations. J Neurosurg 65(4):476-483

23. van Swieten JC, Koudstaal PJ, Visser MC, Schouten HJ, van Gijn J (1988) Interobserver agreement for the assessment of handicap in stroke patients. Stroke 19(5):604-607

\section{Comments}

This study addresses functional and educational outcomes in children who underwent multimodality treatment for intracranial arteriovenous malformation (AVM) in the authors' institution. They report on a cohort of 25 children treated between 1998 and 2016 who were followed up for a mean of 11.5 years (range 4.1 to 24.4 years). They conclude that the educational attainment of these children was not different to agematched controls in the Netherlands. Although this study is relatively small, and does not directly address cognitive function in these children, it demonstrates that thoughtful multistage and multimodality treatment of AVM's in children does not compromise their long-term educational outcomes. The authors also refer to the value of access to good rehabilitation services. This is a valuable addition to the literature on long-term outcomes of intracranial AVM's in children.

Kristian Aquilina

London, UK 